\title{
Child Safety
}

G Ulziibayar, Selenge, E Ganbaatar, D Dambadarjaa. School of Public Health, Health Sciences University, Ulaanbaatar, Mongolia

The leading cause of infant and under 5-years' child burn mortality was contact with hot drinks and foods (31.6\%, 45.6\%) in 2009. According to the study report of Mongolia, the median age of child death of burn was 3.0. Therefore child burn is the public health priority issues that need comprehensive policies and measures in order to reduce the incidence of child burn in Mongolia. The aim of the study was to determine the incidence of child burn among Ulaanbaatar. The study involved a total number of 793 children of 711 families from the Ulaanbaatar, randomly. The age range was 05 , of which $50.7 \%$ were boys. $51.3 \%$ attend in daycare centers. $17.9 \%$ of the total surveyed children were injured within the last year, of which $8.1 \%$ were resulted from burns.

83.3\% of burned children were at home when accidents happened. $41.7 \%$ of the surveyed family members stated that the children burned themselves. The family members were asked during the survey: "what to do when your child gets burned". Out of the total, $38.7 \%$ indicated that they would treat it by soap, $49.1 \%$ by sugar, $39.6 \%$ by blood of dogs, and of which $51 \%$ would treat by raw meat. This study identified that almost all of these burn incidents occurred in environment among the children under 5- years old. This study concludes that the family members have inadequate knowledge about child accident prevention program and the first-aid treatment. 